\title{
Making Time for Dissertation Grants
}

\section{Strategies for Social Work Students and Educators}

Leslie K. Hasche

George Warren Brown School of Social Work, Washington University

Brian E. Perron

School of Social Work, University of Michigan-Ann Arbor

Enola K. Proctor

George Warren Brown School of Social Work, Washington University

Grant writing is a necessary skill for becoming an independent and successful social work researcher. Since social work dissertation grants are a relatively new trend, students face many challenges in identifying, preparing, and submitting dissertation grants. Lack of resources and experiences, difficulties in protecting time for grant writing, and the uncertainty of success can hinder work on dissertation grants. Thus, this article provides an overview of dissertation grants, including a review of grant mechanisms, suggestions for preparing grants in the context of program milestones, and identifying institutional infrastructure to facilitate submissions. Strategies discussed include how to learn about funding priorities, how to establish timelines to account for grant deadlines, and how to use peer reviews to guide the revision process.

Keywords: $\quad$ grant writing; doctoral education; research infrastructure; dissertation grants

G rant writing is a necessary skill for becoming an Jindependent and successful social work researcher (Gambrill, 1994). Thus, acquiring experience with grants early in one's career-such as through preparing a dissertation grant-offers numerous benefits. A successful dissertation grant provides financial resources that support contact with external consultants, protects time for completing the dissertation, and allows for more extensive data collection or data analysis. A student can still reap many benefits by submitting grants, even if the grant is not funded. That is, grant-writing tasks develop skills and experiences that are important to potential employers, provide a basis for future work, and prepare doctoral students for the competitive funding environment.

Social work dissertation grants are a relatively new trend, with most successes being confined to a handful of institutions and funding sources (Austin, 1999). This limited experience within the field creates many challenges for students in identifying, preparing, and submitting dissertation grants. Moreover, social work doctoral training is rigorous, time limited, and replete with competing demands. Thus, it is important to know how and where work on dissertation grants can fit in the educational process.
Prior articles have focused on specific grant mechanisms that are relevant to social work researchers (e.g., Holleran \& Thompson, 2005; Langhorst \& Svikis, 2007; Leukefeld \& Ries, 1993), and other journals have published career development articles for advanced graduate students in social science disciplines (e.g., Cohen, 2002; Wuffle, 1998, 2006; Simien, 2002). Yet there are a limited number of articles related to the training of social work doctoral students (e.g., Proctor, 1996; Khinduka, 2002) and grants to support their doctoral education (Grinstein-Weiss, 2006). To help fill this gap in the social work literature, this article provides an overview of dissertation grants for doctoral students. In this article, we present information on both grant mechanisms that specifically target dissertation research or concurrent

\footnotetext{
Authors' Note: The authors acknowledge support from the National Institute of Mental Health's predoctoral trainees program (IT32MH199960) at the Center for Mental Health Services Research at the George Warren Brown School of Social Work, Washington University. Please address correspondence to Leslie K. Hasche, George Warren Brown School of Social Work, Washington University, One Brookings Drive, Campus Box 1196, St. Louis, MO 63130; e-mail: lhasche@wustl.edu.
} 
training and other nonspecific grants that could be used to support dissertation research.

In order to reach the broadest audience possible, this article does not focus on any specific grant mechanism or reflect the structure of any particular doctoral program. Instead, this article provides an overview of various funding sources and grant mechanisms, strategies for selecting which grants to pursue for dissertation funding, and suggestions for preparing a grant within the context of program milestones. Recommendations for resubmitting a grant and managing rejection are also discussed. The article concludes with strategies a doctoral program may use to enhance its research infrastructure and to help support doctoral students prepare dissertation grants.

\section{Overview of Dissertation Grant Mechanisms}

An important first step in securing a dissertation grant is learning about various funding opportunities for a substantive area. This work can occur well before a specific dissertation is proposed, even during the 1st year of doctoral education. Appendix A provides a list of various public and private Web resources that can be used to facilitate the process. Potential funding sources can also be identified by working closely with researchers within the social work department and consulting with national experts in the respective substantive area. Whoever supports existing research in one's substantive area is a great place to start. Attending conferences, such as the Society for Social Work and Research or the Council on Social Work Education, can give the student a chance to speak directly with representatives (i.e., program officers) of both public and private funding sources at the exhibit hall or formal presentations. These activities provide essential information for the subsequent steps in the process.

\section{Grant Mechanisms}

The next step involves finding the appropriate grant mechanism within the funding source for dissertation research projects. Grant mechanisms are characterized by several factors, including eligibility for the individual researcher and the institution, the stated research priorities and objectives of the grant, the intended allowable costs if the grant is funded (i.e., the specifics of how a researcher may spend the money for stipends, training, personnel, consultations, and purchase of supplies, etc.), and deadlines and waiting periods for award notices. For dissertation grants, a variety of mechanisms are available from public and private funding sources, which are overviewed in the following sections.
Table 1

Examples of Public and Private Funding Sources for Social Work Dissertation Grants

Examples of Public Funding Sources

Administration for Children and Families

Agency for Healthcare Research and Quality

Centers for Disease Control and Prevention

Department of Defense

Department of Housing and Urban Development (HUD)

Department of Veterans Affairs

National Academy of Science

National Institute of Aging (NIA)

National Institute of Alcohol Abuse and Alcoholism (NIAAA)

National Institute of Child Health and Human Development (NICHHD)

National Institute of Drug Abuse (NIDA)

National Institute of Mental Health (NIMH)

National Institute of Justice (NIJ) of the U.S. Department of Justice National Science Foundation (NSF)

Substance Abuse and Mental Health Services Administration

Examples of Private Funding Sources

Academic Council of the United Nations System

American Association of University Women

American Cancer Society

American Foundation for Suicide Prevention

Fahs-Beck Fund for Experimentation and Research

Guggenheim Foundation for Violence Research

Hartford Geriatric Social Work Doctoral Fellows Program

Influencing State Policy-Dissertation Award

NASW Foundation Doctoral Fellowships

Nonprofit Sector Research Fund

Phi Delta Kappa

Robert Wood Johnson Foundation

Society for the Scientific Study of Sexuality

The Melissa Institute

The Woodrow Wilson National Fellowship Foundation

Publicly funded grants. Several publicly funded grant mechanisms are available for students through government institutes and centers. Although not limited to this list, Table 1 provides some examples. Many publicly funded grants use the same nomenclature to describe grant mechanisms, such as the Agency for Healthcare Research and Quality (AHRQ), the Centers for Disease Control and Prevention (CDC), and the National Institutes of Health (NIH). Here, although the research priorities may vary by funding source, the same letters followed by numbers are used to designate grant mechanisms, and this includes $R=$ Research Grants or Small Business Grants; $K=$ Research Career Development Grants; $F=$ Individual Training Fellowships; $T=$ Institutional Training Fellowships (i.e., university- or department-level); and $P=$ Program Project Grants/Center 
Grants. Of note, eligibility requirements often include enrollment in a doctoral program and U.S. citizenship or permanent residence. The following descriptions include 2008 deadlines; thus students are encouraged to verify deadlines with the funding sources, as these may change periodically. Common federal grant mechanisms for social work dissertations include the following.

F31, the National Research Service Awards for Individual Predoctoral Fellowships. This training grant requires a dissertation research plan, a formal training plan, and a sponsoring mentor who should be an active researcher in the student's proposed area. Funding covers generally 2 to 3 years and includes for fiscal year 2007 a stipend of $\$ 20,772$ along with $\$ 4,200$ of trainingrelated expenses. Since the review criteria for this grant is unique in considering the training plan, a checklist of recommended questions to address in the application is provided in Appendix B. Deadlines include April 8, August 8, and December 8.

R03, the Small Research Grant Program. This grant supports small, time-limited projects (dissertation or otherwise) with maximum annual funding of $\$ 50,000$ for 1 to 2 years. Deadlines include February 16, June 16, and October 16.

R36, the Dissertation Research Grants to Increase Diversity. The purpose of this grant is to promote doctoral candidates from underrepresented groups (e.g., racial, ethnic, disabled, and disadvantaged backgrounds) with a maximum $\$ 35,000$ funding for 2 years. Deadlines include February 16, June 16, and October 16.

National Institute of Justice Graduate Research Fellowship. This annual program supports research regarding crime and justice for doctoral students from any academic discipline at an accredited university or institution. Approximately 10 awards of $\$ 20,000$ are anticipated to be granted, with costs designated to cover the dissertation research work. The deadline is November 28.

National Science Foundation Doctoral Dissertation Research Improvement Grants. To develop innovative methods and models for the behavioral and social sciences, this grant provides a maximum of $\$ 12,000$ for up to 2 years. The allowable costs include data collection, subject payment, and equipment. However, no stipend is allowed for the student researcher. Uniquely, this grant also requires that the student's advisor is listed as the principal investigator, while the student is a co-principal investigator. Deadlines include: January 16 and August 16.

Privately funded grants. Privately funded grant mechanisms may provide support for dissertation-specific work (i.e., data collection, secondary data analysis, dissemination), for local program evaluation efforts, for research on a substantive area, for training to promote underrepresented groups in academia, or for specific methodological strategies (i.e., intervention development and testing). Although some private foundations have long-standing records in funding social work dissertations, the funding opportunities change rapidly, thus requiring close monitoring of the foundation's Web sites, communication with other researchers and program officers, and attention to deadlines. Eligibility criteria and deadlines are unique to each foundation and each specific grant mechanisms. Coverage of allowable costs can vary by requirements for use through stipends, training, or costs of conducting research. There is also significant heterogeneity in overall budgets and allowable costs. Budgets may range from $\$ 500$ per year up to $\$ 50,000$ for 2 years. A comprehensive listing of private funding sources for social work dissertation grants was included in the Institute for the Advancement of Social Work Research's (IASWR's) recent online publication "Funding Opportunities for Doctoral, Dissertation, and Post Doctoral Studies" at http://charityadvantage .com/iaswr/DoctoralfundingUPDATEDBBMarch2008. pdf. A few common privately funded dissertation grants are listed in Table 1, which includes the following.

Fahs-Beck Fund for Research and Experimentation. With a broad, social work-relevant priority of supporting research and understanding or intervening to improve the functioning or well-being of children, adults, couples, families, or communities, this funding source provides up to $\$ 5,000$ dissertation support. Applications are due on May 1 or November 1, and it includes a 2-page abstract, a copy of the student's dissertation proposal, curriculum vitae, budget, timeline, and proof of committee approval and institutional review board approval.

Hartford Doctoral Fellowship. For dissertations aimed at "improving the health and well-being of older persons and their families," this funding source provides $\$ 25,000$ per year for up to 2 years. This grant does require some cost sharing from the student's university, in which the university provides an additional $\$ 10,000$ per year through tuition waivers, research assistantships, teaching assistantships, or other scholarships. Deadlines occur twice a year, at February 1 and August 1. 
Guggenheim Foundation. With a priority to increase understanding on the causes, manifestations, and control of violence, this grant provides $\$ 15,000$ to support doctoral candidates in their "writing phase" of their final year of study. The deadline occurs once per year on February 1.

Some universities may also offer financial support for dissertations. Again this can vary depending on the availability of funds and how money is distributed within universities. It is worth a student's exploring options within the school of social work with the doctoral chair, advisors, and potentially the dean. Furthermore, a student should look beyond the department to the larger university. Interdisciplinary research centers that are organized around a given topic (i.e., Center on Aging, Center for Ethics, etc.) may provide small research grants. Also, university-wide competitive grants may exist within the Graduate School of Arts and Sciences or other faculty associations (i.e., Association of Women Faculty) for which social work students could apply.

\section{Matching Funding Priority Areas to the Student's Interests}

Once a student is familiar with potential funding sources and the structure of grant mechanisms, the next step involves an iterative process of identifying how the funders' priority research areas match the student's interests. Here, the student's interests may not change, but how he or she writes about it does go through multiple revisions. The student alternates between narrowing the scope of one's research interests while refining how those interests are expressed in relation to the priority areas of funding sources.

First, the student can start by framing his or her work in relation to a specific substantive issue (e.g., intimate partner violence, substance use, civic engagement), population of interest (e.g., children, single mothers, Latinos), or methodology (e.g., instrument development and validation, system dynamics modeling). Literature reviews and writing assignments can facilitate how the student articulates the significance of the research area. This process often involves familiarizing oneself with the epidemiology of a problem (i.e., prevalence rates, course) and the impacts on individuals, families, organizations, and the larger community and society. Often, this work is expressed as the costs to society or public significance.

Next, a student can examine how one's research area matches or creatively overlaps with the priorities and mission statements of public and private funding sources. This work will further help identify how to frame one's interest by using the funding sources' terminology and statements of why such research is important. By exploring potential grant sources, the student begins to identify the research questions, populations, terminology, and variables of interest specified by the funding source's priorities. Trends in research priorities may alternate between substantive areas related to national initiatives such as the Healthy People 2010 objectives (U.S. Department of Health and Human Services, 2000), current events (i.e., immigration, veterans issues), and newly recognized societal problems (i.e., human trafficking, substance use among older adults). The funding source's mission statement, recent publications, and previously funded grants are good sources of information. Furthermore, by recognizing these priority areas, a student can make informed decisions about which grant application has the highest likelihood for payoff.

\section{Program Announcements and Request for Proposals}

Specific sources of information regarding funding priorities are broadly referred to as Funding Opportunity Announcements (FOAs) or, more specifically, as program announcements (PAs), request for proposals (RFP), and request for applications (RFA). Program announcements are broad requests for applications to conduct funded research in a scientific area, such as the Robert Wood Johnson Foundation's (2008) program announcement on Active Living Research-which includes designated dissertation awards. This announcement invites research that develops knowledge about environmental and policy strategies that increase physical activity in order to prevent childhood obesity. Similarly, the PA from the CDC (2007) for Public Health Research Dissertation (R36), PAR-07-231, broadly solicits grants from doctoral students of any discipline who have methodological and research interests related to prevention and the control of disease, injury, and disability.

As an alternative, RFP's or RFA's are specific, timelimited announcements for funding opportunities from a research institute to use certain grant mechanisms for targeted objectives such as Research on HIV/AIDS and Drug Use in the Multicenter AIDS Cohort Study (MACS) from the National Institute of Drug Abuse (2007). This RFA focused on partnering with an existing longitudinal study for secondary data analysis or other collaborative research studies to investigate an extensive list of interest areas (R03), RFA-DA-08-008. Private foundations offer general program objectives, such as the John A. Hartford Foundation's Doctoral Fellows 
Program, which states: "Expand the number of social work doctoral dissertations that identify and examine a set of research questions that seek to improve the health and well-being of older persons and their families" and "cultivate the next generation of geriatric social work faculty" (The John A. Hartford Geriatric Social Work Initiative, n.d., p. 2).

Generally speaking, these announcements include details about which funding sources or institutes are interested in sponsoring the research, what specific grant mechanisms are available, the application requirements, the timelines for funding, and the contact information for program officers. A program officer (or sometimes called program director or coordinator) is the primary contact person for the grant who can answer questions about the funding source, the types of research sought, and the details of the grant application. Program officers will often discuss with potential grant applications how one's proposed dissertation work fits within the given funding source's priorities. They can also provide suggestions for how to strengthen one's application or for redirecting the grant to an alternative funding source that may be more appropriate. These announcements and contact with the program officers can help tailor the argument for the significance of one's research to the specific review committees. Citing directly how the dissertation responds to these research priorities and using the announcements' language and terminology helps connect the proposed research to their funding interests.

\section{Strategies for Overcoming Gaps in Funding Areas}

Although a variety of options are now available to fund dissertation research, substantive areas do not always match the funding priorities; eligibility requirements leave some doctoral students with minimal options, and the competition for such funding is still fierce. Social work doctoral students' research interests do include the traditional domains listed by Austin (1999) of child welfare, mental health, health, HIV/AIDS, gerontology, poverty, social policy, issue's affecting women, and substance abuse. For some of these areas along with others that were unlisted (i.e., reproductive rights, spirituality and religion, LGBT issues, immigration), public and private research priorities may omit these topics.

First, students should see if they qualify for grant mechanisms that do not specify research priority areas. Private and public grant mechanisms exist that focus on the development of diverse researchers and academics and not on specific research issues. These mechanisms promote researchers with diverse backgrounds and characteristics and may offer support to specific racial or ethnic groups and persons with disabilities.

Second, students may face decisions about staying true to their research interests or modifying their research interests to match a particular funding source (Yang, 2005). A variety of strategies can be potentially helpful. For example, mentors can help a student frame one's interests in relation to important outcomes of current research priorities. The student can use course papers and concept papers to develop a strong, coherent, yet concise argument for the significance of one's research area and why the dissertation work is needed to fill gaps in knowledge. When a student chooses to use a dissertation topic related to but not exactly one's first choice (i.e., to match current funding priorities), this work can provide opportunities to develop needed research skills and knowledge. It is even possible that the dissertation findings may strengthen the call for future research on the preferred substantive area.

Lastly, another challenge involves the U.S. citizenship eligibility requirement, which leaves many international doctoral students with few funding choices. It is clearly a gap in our knowledge and in availability of funding that has yet to be remedied. Examples do exist of international students receiving private grants and supplementing their dissertation work with teaching and research assistantships.

\section{Planning the Grant}

Advanced preparation is essential to any successful grant. The time needed for completing a grant application is estimated to be between 9 months and 1 year (Proctor \& Stiffman, 2002). Timing is especially important with dissertation grants given the time-limited process of doctoral education and the need to continue working toward program milestones. Moreover, many grants are not awarded during their initial submission, so it is often ideal to allow some time for a resubmission or to pursue multiple funding sources. Thus, a timeline helps track the grant preparation activities and facilitate a writing schedule that includes both grant work and program milestones. In fact, developing this timeline with one's chair becomes a beneficial communication tool to discuss objectives and specific tasks needed from the chair, the student, and the rest of their dissertation committee. Grant deadlines provide incentives to students to complete the program milestones and prompt committee members to provide feedback in a timely manner. Examples of how two doctoral students balanced program 
Table 2

Example Timelines of Doctoral Education and Dissertation Grant Activities

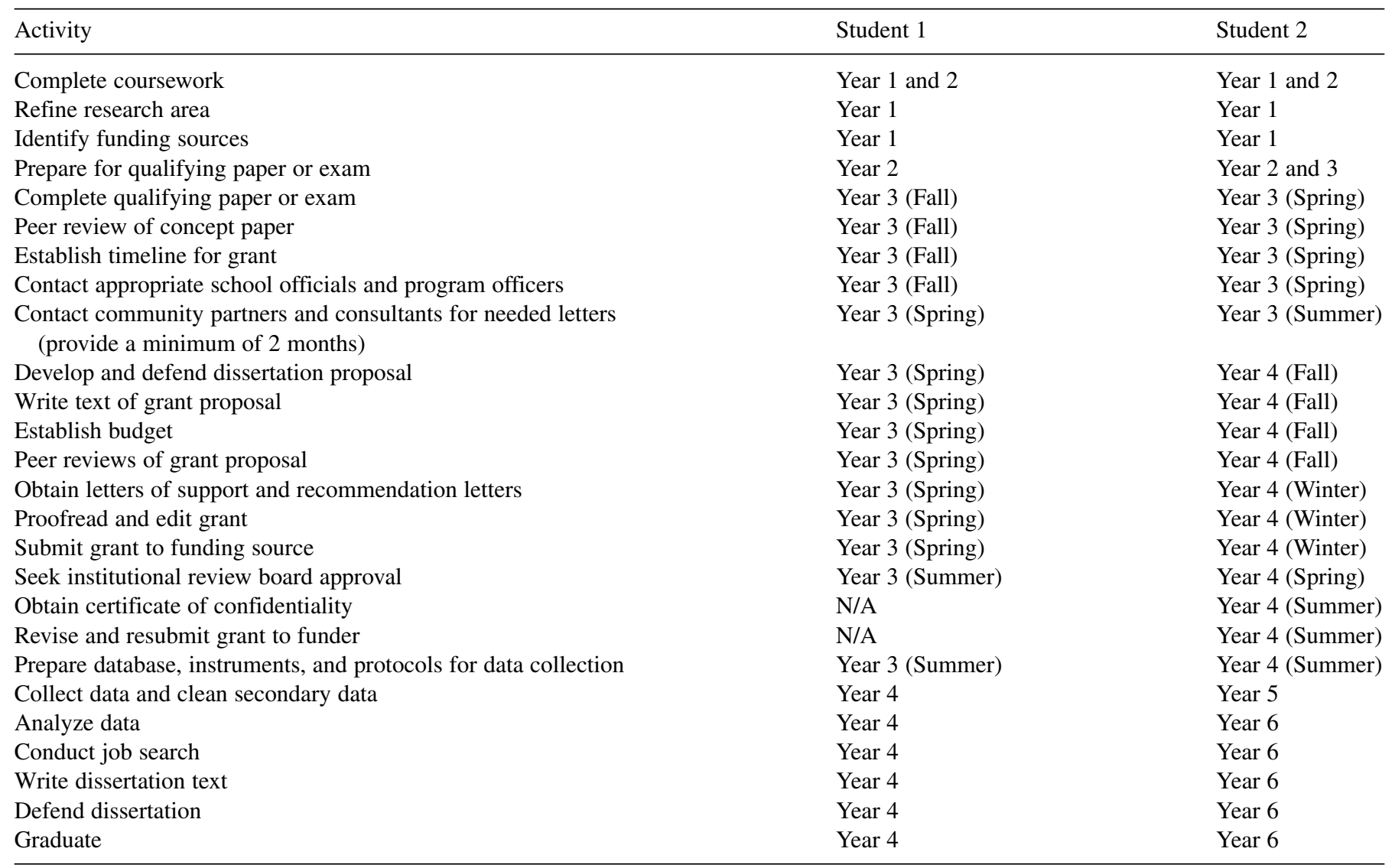

milestones and grant-writing activities are provided in Table 2.

The timeline will also require attention to nonstudy features, including the administrative aspects such as developing a budget, planning for personnel, connecting with potential collaborators in practice settings, obtaining letters of support, and navigating the process of the institutional review board (IRB). Furthermore, social workers planning to collect data with vulnerable populations about sensitive information (i.e., drug use, illegal activity) should anticipate an extended IRB approval owing to the process of obtaining a Certificate of Confidentiality. A Certificate of Confidentiality provides a level of protection against forced disclosures of identifiable information on research participants in civil, criminal, administrative, legislative, or other proceeding at the federal, state, and local level. Regardless of whether the research is federally funded, this certificate may be obtained from the National Institutes of Health, and it is estimated that the application process will take an additional 3 months following a researcher's obtaining approval from the university-specific IRB Board (see http://grants1.nih.gov/grants/policy/coc/index.htm).

\section{Review Examples of Grant Applications}

Along with paying close attention to the instructions of the grant application, it is helpful to review successful grants and use these as a guide to what textual and administrative pieces are required. These grants can offer insight on how to overcome certain study limitations, to develop strategies for organizing a large body of information in a small amount of space, and tips for making writing as concise and precise as possible. As some schools of social work already archive submitted grants, contacting the school's respective department may be the first step. Furthermore, funded grants are considered to be part of the public domain of information. Thus, students should feel free to contact either the principal investigator for a copy of the grant or ask the program officer for examples of successful grants.

\section{Conduct Peer Reviews}

The preparation of the grant should not be removed from the peer-review process. In fact, most successful researchers would acknowledge the importance of using peer review at every stage of the research process. The 
student can develop a concept paper outlining the general ideas to be reviewed by their fellow students and one or two faculty mentors. Concept papers can be as brief as four pages and contain the primary logic and methods of the grant. Sections can include (a) the significance of the issue, (b) the research aims and hypothesis, (c) a conceptual model, (d) a brief description of the theoretical basis, and (e) an outline of proposed methods. The reviewers' verbal or written feedback may be shared during an hour-long meeting to discuss the scientific importance, feasibility, and critiques of the work. Ideally during this time, the student gathers information, provides minimal clarification, and seeks input for future decisions. Within the last few months of grant preparation, one or two more peer reviews of the full grant application are crucial. During these reviews, it is also good to provide the peer review participants with information about the funding source and the grant mechanism. These reviews will help with refining, marketing, and clarifying the research aims, use of theory, and methods for the funding source's review committee. For example, peer reviews can help streamline the use of background literature so that a coherent, theoretically driven argument is presented for the significance of the dissertation and the selection of one's methodological approach.

When organizing the peer review sessions, one should consider the composition of participants and the intended purpose. While having a large number of review participants is often beneficial, a select set of peer reviews may have greater payoffs. These persons may be selected because of their methodological or substantive expertise. Persons outside the area of study can help determine the extent to which the writing is comprehensible. It is also helpful to instruct persons on what to review. For example, work in the early stage may not be ready for line editing; whereas, a review in the last month of the grant can benefit from multiple reviewers providing proofreading comments.

\section{Revise, Revise, and Revise}

This intensive preparation of the application provides time for multiple revisions, refinements, and feedback so that the application best argues why one's dissertation deserves funding over the other applicants. Following each school's established procedures for submitting grants, the final week of grant submission should allow time for careful line editing by the student and a separate individual with editing skills (i.e., writing lab at one's university, fellow student, etc.). This editing is no longer for substantive content but to ensure proper grammar, writing structure, and clarity in style. Finally, the student is ready to ship the entire grant (and any required copies) with a guarantee overnight service to arrive at funding source on the day of the deadline. Achieving this point is a major accomplishment, regardless of the outcome.

\section{Managing Rejection and Resubmission}

Only a small fraction of grants are funded on their first submission. Students should be aware of the high rejection rate and strive to submit the highest quality grant application. At the same time, students should remain cognizant of the skills and experiences that will be acquired even if the grant is not funded. If the doctoral grant is not funded on its first submission, students should actively consider a resubmission. This decision will be influenced by numerous factors such as the funding source's resubmission guidelines, the context of timing in relation to achieving other program milestones, and the grant reviewers' feedback.

Depending on the review process, grants receive scores and varying amounts of reviewers' comments. The reviews will provide guidance on how much additional work is needed and on the likelihood of success upon resubmission. It is helpful to convert the narrative reviews into a table that systematically summarizes both the strengths and weaknesses of the grant. This kind of presentation can ensure the strong points of the grant are retained. For the identified weaknesses, it is important to recognize reviewers are experts in the field and their criticisms should be considered opportunities for improvement. Students will undoubtedly benefit from the continued guidance from experienced faculty members in this process. Many resubmitted grants are allowed a few pages of introduction to the revised grant as an overview for the review committee (which is often composed of the same members who previously reviewed it). Thus, this table can be included or used as an organizing outline for the resubmission's introduction. For grants that are returned with minimal or no reviewers' comments, the student may contact the program officer to learn about any oral feedback provided during the review meeting.

Students who choose not to resubmit their grant should examine all the possibilities of using the existing grant application for future work. It is assumed that much of the doctoral grant application will fold over into the student's dissertation. Furthermore, the suggestions from the reviewers may provide new ideas, allowing for a revised and expanded version of the grant to be submitted later in one's career. For example, one common critique of dissertation grants is the concern for the feasibility of completing the research activities within the 
limitations of the dissertation timeframe and by a new investigator. Thus, many ideas that may be too ambitious at the dissertation level can be quickly turned into research proposals for funding when one is a junior faculty.

\section{Infrastructure to Support Doctoral Students}

There is a growing development of interest in research grants among social work doctoral students. However, since the amount of research money available is finite and eroding it is increasingly difficult to develop infrastructure that supports doctoral students in preparing dissertation grants. Outlined below are various strategies used by different social work departments that rely primarily on the existing knowledge and experiences of the faculty.

\section{Formalized Peer Reviews}

As previously discussed, peer review is an important part of the grant-writing process. Structured peer review sessions organized by faculty can be an effective way of building an infrastructure to support doctoral dissertation grants. Such sessions can serve to normalize the process of seeking, receiving, and using critical peer feedback; sharpen students' ability to read critically and provide constructive feedback to others; facilitate students' progress in writing concept papers and research proposals; and encourage students to send draft proposals to experts and funding organizations. Students can learn that the peer review process ensures that the highest quality applications are successful. Faculty and students can consider organizing a routine schedule for peer reviews in conjunction with other doctoral student meetings.

\section{Research Methods Course}

Various social work doctoral programs have integrated grant writing into their respective research methods courses. This provides students with early exposure to a primary vehicle through which a significant portion of the research is conducted. For example, a final paper for the course could be a draft of a small research grant proposal that is intended for a specific funding source, as selected by the student or instructor. Course activities can include assignments that review funding priorities and that articulate how the student's interests match these priorities. Course readings in substantive classes may include national or international reports on priority problems, such as Surgeon General Reports, Blue Ribbon Reports, or other consensus statements on the state of research in a given substantive area.

\section{Mock Review Sessions}

Mock review sessions can also be incorporated into the coursework or into the peer review sessions by having students assume the role and responsibilities of a funding source's review committee. Many funding sources make public knowledge their review criteria and procedures. In fact, the National Institutes of Health has provided a videotape of a review committee along with the written grants and reviewer comments as an instructional tool (National Institutes of Health, 2007). Furthermore, the peer review sessions may assign primary and secondary reviewers who are responsible for summarizing and critiquing a student's grant proposal, as a means of familiarizing the students with the grant process.

\section{Student and Expert Workshops}

Student groups can work closely with faculty to develop sessions on funding opportunities, various grant mechanisms, and general strategies for preparing a grant. For example, 4th-year-and-above students can share their grant experiences with the 1st- and 2nd-year students as an easy way to communicate institutional knowledge through the cohort of students. Expert workshops may include coordinating question-and-answer sessions with junior faculty members who may have recently and successfully written dissertation grants, with senior faculty members or guest lecturers who may be involved in public or private review committees, and with instrumental university staff members who can assist with the logistics of grant preparation (i.e., a representative from the human subjects committee, the university's grant administrator for budget development, etc.).

\section{Awareness of Funding Sources}

Proctor (1996) stated that schools of social work can build faculty connections to funding sources through a variety of strategies, including distributing announcements regularly and promptly to faculty, making funding searches routinely available to faculty members, and maintaining a resource file on funding agencies and their priorities, announcements, and application procedures. These same strategies have been effectively applied to support the doctoral students in preparing a grant and becoming knowledgeable about the various mechanisms and processes for carrying out their future research.

\section{Institutionalizing Knowledge}

There is an extensive literature showing that institutional knowledge requires the preservation of experiences and 
information. Faculty members can encourage students to document and share their completed written grants or "lessons learned," thus becoming part of the school's resources and formalizing the institutional knowledge. Formalized seminars on the above topics can also provide an opportunity for students to be informed early in their educational process.

\section{Discussion and Applications to Practice}

This article provided an overview of dissertation grants for doctoral students-who as future researchers and educators will be integral in expanding the knowledge base for social work practice. In doing so, it is important to note that there is no one-size-fits-all approach for how dissertation grants contribute to the career trajectories of doctoral students. The suggestions are intended to provide very general guidance, facilitate the development of feasible timelines, and highlight important decision points. Furthermore, owing to the numerous possibilities of dissertation funding sources and the revolving nature of available funds, this article is limited because not all potential sources of support are reviewed in detail. The student will have to supplement and adapt this information, preferably under the tutelage of an experienced social work faculty member. Finally, it is also important to note that dissertation grants should be regarded as a means to an end, with the ultimate goal of producing useful knowledge on important social problems and social work practice. There are many successful social work researchers who have made important contributions to the knowledge base without grant support. Nonetheless, the support afforded to students through dissertation grants can offer beneficial career opportunities and help advance a particularly important line of research.

\section{Appendix A Helpful Web Sites}

\section{United States Federal Government}

Searchable Site with more than 1,000 grant programs and applications from 26 federal agencies. http:// www.grants.gov/
Searchable site for federally funded grants (to get ideas of how studies in your area have been funded). http://www.crisp.cit.nih.gov/ or http:// taggs.hhs.gov/AdvancedSearch.cfm

Centers for Disease Control and Prevention. http://www.cdc.gov/about/business/funding.htm

National Institute of Justice. http://www.ncjrs.gov/ pdffiles1/nij/s1000794.pdf

The National Academies. http://www7.nationalacademies.org/fellowships/othfells.html

\section{United States, National Institutes of Health}

Institutes, centers and offices: The individual organizations that make up the NIH. http://www.nih .gov/icd

NIH funding opportunities and notices (searchable). http://grants1.nih.gov/grants/guide/index.html

Writing an NIH grant application: Grant tutorials. http://www.nlm.nih.gov/ep/Tutorial.html

Standard application receipt dates for NIH grant applications. http:/grants.nih.gov/grants/funding/ submissionschedule.htm

Ruth L. Kirschstein National Research Service Award (NRSA) stipend and other budgetary levels effective for Fiscal Year 2007. http://grants.nih.gov/ grants/guide/notice-files/NOT-OD-07-057.html

Instructions for obtaining a certificate of confidentiality. http://grants1.nih.gov/grants/policy/coc/ index .htm

\section{Other Sites Listing Dissertation Grant Opportunities}

Institute for the Advancement of Social Work Research (IASWR): Funding opportunities for doctoral, dissertation, and postdoctoral studies. http://charityadvantage.com/iaswr/Doctoralfundin gUPDATEDBBMarch2008.pdf

IASWR links and resources. http://www.iaswresearch.org/

The Foundation Center. http://fdncenter.org

FundSource From Decade of Behavior. http://www .decadeofbehavior.org/fundsource/

The Social Science Research Council. http://fellowships.ssrc.org/ 


\section{Appendix B \\ Review Criteria for NIH F31 Individual Predoctoral Fellowship Mechanism}

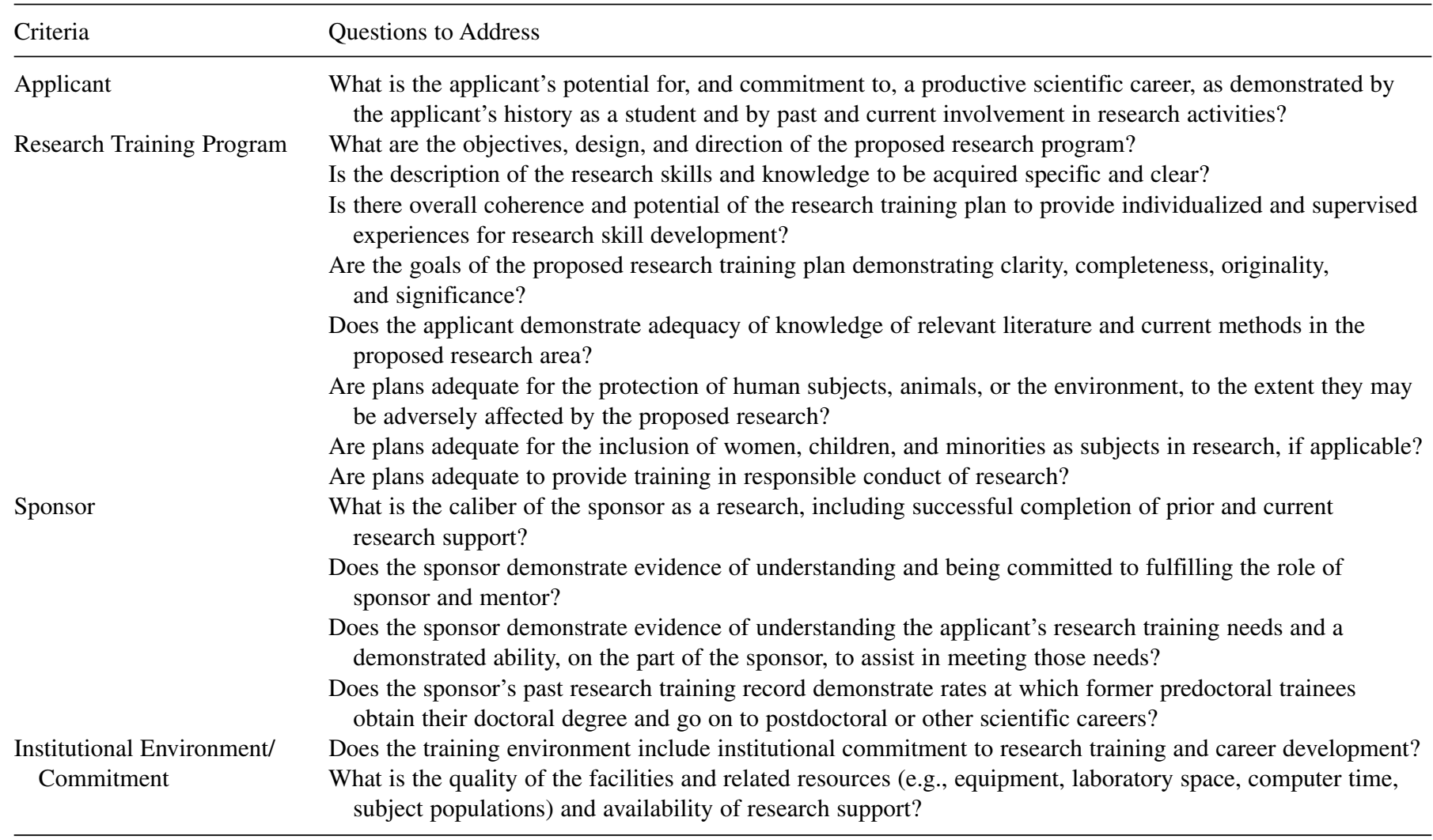

Adapted from Zayas (2005). This handout was based on National Institutes of Health material and developed with the support of the Center for Mental Health Services Research at Washington University.

\section{References}

Austin, D. M. (1999). A report on progress in the development of research resources in social work. Research on Social Work Practice, 9, 673-707.

Centers for Disease Control and Prevention. (2007). CDC grants for public health research dissertation (R36). Retrieved May 15, 2008, from http://grants.nih.gov/grants/guide/pa-files/par-07231.html

Cohen, D. B. 2002). Surviving the Ph.D.: Hints for navigating the sometimes stormy seas of graduate education in political science. PS: Political Science and Politics, 35, 585-588.

Gambrill, E. (1994). Social work research: Priorities and obstacles. Research on Social Work Practice, 4, 359-388.

Grinstein-Weiss, M. (2006). Funding opportunities for social work doctoral students through the U.S. Department of Housing and Urban Development. Research on Social Work Practice, 16, 632-637.

Holleran, L. K., \& Thompson, S. J. (2005). The NIH K-Award: Funding opportunities for social work researcher. Research on Social Work Practice, 15, 301-308.

The John A. Hartford Foundation Geriatric Social Work Initiative. (n.d.) Geriatric Social Work Initiative Doctoral Fellows Program Application Information. Retrieved August 15, 2007, from http://www.geron.org/Hartford/DoctoralApl.pdf

Khinduka, S. (2002). Musings on doctoral education in social work. Research on Social Work Practice, 12, 684-694.
Langhorst, D. M., \& Svikis, D. S. (2007). The NIH RO3 Award: An initial funding step for social work researchers. Research on Social Work Practice, 17, 417-424.

Leukefeld, C. G., \& Ries, J. B. (1993). Strategies to compete for federal grant funding for research on social work practice. Research on Social Work Practice, 4, 208-218.

National Institutes of Health. (2007) Inside the NIH Grant Review Process. Retrieved February 13, 2007, from http://www .csr.nih.gov/Video/Video_print.asp

National Institute of Drug Abuse. (2007). Research on HIV/AIDS and Drug Use in the Multicenter AIDS Cohort Study (MACS). Retrieved August 15, 2007 from http://grants.nih.gov/grants/ guide/rfa-files/RFA-DA-08-008.html

Proctor, E. K. (1996). Research and research training in social work: Climate, connections, and competencies. Research on Social Work Practice, 6, 366-378.

Proctor, E. K. \& Stiffman, A. R. (2002, March). Successful grants. Paper presented at the University of Texas, School of Social Work Substance Abuse Research Development Program, Austin, TX.

Simien, E. M. (2002). On the market: Strategies for the successful job candidate. Political Sciences and Politics, 35, 581-583.

Robert Wood Johnson Foundation. (2008). Active Living Research: Call for Proposals-Round 8. Retrieved May 15, 2008 from http://www.rwjf.org/files/applications/cfp/cfp_ALR8.pdf

U. S. Department of Health and Human Services. (2000). Healthy people 2010: Understanding and improving health (2nd ed.). Washington, DC: Author. 
Wuffle, A. (1989). Uncle Wuffle's advice to the advanced graduate student. PS: Political Sciences and Politics, 30, 213-216.

Wuffle, A. (2006). Uncle Wuffle's advice on job talks. PS: Political Science and Politics, 39, 883-886.

Yang, O. O. (2005). Guide to effective grant writing: How to write an effective NIH grant application. New York: Kluwer Academic/ Plenum.

Zayas, L. H. (2005, October). Comparative view of the review criteria for three types of NIH funding mechanisms. Paper presented at the meeting of the Center for Mental Health Services Research T32 Research Training Program, Saint Louis, MO.

Leslie K. Hasche, MSW, is a doctoral candidate at the George Warren Brown School of Social Work at Washington University. Her research interests include the organization and practice of mental health care for older adults.
Brian E. Perron, PhD, is an Assistant Professor of Social Work at the University of Michigan. He studies services for persons with serious mental illness and substance use disorders, with an emphasis on comorbidities.

Enola K. Proctor, PhD, is the Frank J. Bruno Professor of Social Work Research and Associate Dean for Research at the George Warren Brown School of Social Work at Washington University. Her research agenda provides direction to mental health service delivery in social work settings and the use of evidence-based practice principles. 